\title{
The Effects of Vocational Training Programmes on the Duration of Unemployment in Eastern Germany*
}

\author{
Reinhard Hujer ${ }^{\dagger}$, Stephan L. Thomsen ${ }^{\ddagger}$, and Christopher Zeiss ${ }^{\S}$ \\ $\dagger J . W . G o e t h e-U n i v e r s i t y$, Frankfurt/Main, IZA, Bonn, ZEW, Mannheim \\ $\ddagger, \S$ J.W.Goethe-University, Frankfurt/Main
}

Working Paper - August 11, 2005

\begin{abstract}
Vocational training programmes have been the most important active labour market policy instrument in Germany in the last years. However, the still unsatisfying situation of the labour market has raised doubt on the efficiency of these programmes. In this paper, we analyse the effects of the participation in vocational training programmes on the duration of unemployment in Eastern Germany. Based on administrative data for the time between the October 1999 and December 2002 of the Federal Employment Administration, we apply a bivariate mixed proportional hazards model. By doing so, we are able to use the information of the timing of treatment as well as observable and unobservable influences to identify the treatment effects. The results show that a participation in vocational training prolongates the unemployment duration in Eastern Germany. Furthermore, the results suggest that locking-in effects are a serious problem of vocational training programmes.
\end{abstract}

Keywords: vocational training, programme evaluation, duration analysis, treatment effect

JEL Classification: J64, J24, I28, J68

\footnotetext{
${ }^{*}$ The authors thank Heinz Galler and an anonymous referee for valuable comments. The paper has also benefited from fruitful discussion at the annual meeting of the German Statistical Society in 2004, Frankfurt, and in IZA seminar, Bonn. All remaining errors are on our own. Financial support of the IAB, Nuremberg, is gratefully acknowledged.

${ }^{\dagger}$ Reinhard Hujer is Professor of Statistics and Econometrics at the J.W.Goethe-University of Frankfurt/Main and Research Fellow of the IZA, Bonn and ZEW, Mannheim, e-mail: hujer@wiwi.uni-frankfurt.de.

${ }^{\ddagger}$ Stephan L. Thomsen is Research Assistant at the Chair of Statistics and Econometrics, J.W.Goethe-University of Frankfurt/Main, e-mail: sthomsen@wiwi.uni-frankfurt.de.

${ }^{\S}$ Christopher Zeiss is Research Assistant at the Chair of Statistics and Econometrics, J.W.Goethe-University of Frankfurt/Main, e-mail: zeiss@wiwi.uni-frankfurt.de.
} 


\section{Introduction}

Unemployment in Eastern Germany is a serious problem. Its burden for the economy is not only a reduced output and consequently a decreased welfare, but also a decay of human capital. Therefore, an efficient labour market policy has to aim at a continuous adjustment of labour supply to the requirements of labour demand. Furthermore, it has to avoid an exhaustion of human capital by the provision of jobs or programmes that improve the individual qualification. The most important aim of active labour market policies (ALMP) is to improve the re-employment chances of unemployed persons. In general, ALMP consist of public employment services, labour market training and subsidised employment. ALMP have become more important over the last two decades which is reflected by their ranking in the EU Employment Guidelines, OECD Jobs Strategy, and the national labour market laws. However, there is no clear evidence on a general effectiveness in the literature. While ALMP were seen as a panacea for the labour market in the early 1990s (as the political emphasis reflects), recent studies disagree. ${ }^{1}$ There may be several reasons for this finding. However, to overcome possible uncertainties, continuous evaluation of the effectiveness and efficiency of ALMP is necessary. ${ }^{2}$

The major element of ALMP in terms of fiscal volume and the number of promoted individuals in Eastern Germany in the last years have been vocational training programmes (Förderung der beruflichen Weiterbildung, FbW). ${ }^{3}$ They aim at the increase of the individual employment probability by qualification transfer. Regarding the tense situation of the Eastern German labour market, programmes are used on a large scale to enhance the economic reorganisation by supply of qualified employees on the one hand, but also to cushion the ongoing employment reduction on the other hand. Furthermore, the use of vocational training programmes may also impose spill-over and general equilibrium effects. If a large number of unemployed individuals are assigned to these programmes, the quantity of labourers with certain skills rises and is thereby likely to lessen its price relative to a situation in which only a modest fraction of the unemployed receives such training (Lechner and Smith, 2005). This may be also a reason for the bad picture in the empirical studies.

There is a number of studies that evaluate the effects of vocational training programmes in East Germany. However, all studies focus on programmes accomplished during the 1990s before the Social Code III was

\footnotetext{
${ }^{1}$ For example, the experiences of Calmfors, Forslund, and Hemström (2001) for Sweden show rather discouraging results from the efforts of the implementation of ALMP on a large scale. See also Hagen and Steiner (2000) and Wunsch (2005) for a review on German active labour market policies and Martin and Grubb (2001) for different OECD countries.

${ }^{2}$ This is one postulation in the EU Employment Guidelines and is also anchored in Social Code III, the legal basis for ALMP in Germany.

${ }^{3}$ In 2000 (the year the programmes under study have started) there were 213,654 entries into the programmes and the fiscal costs amounted to 2,748.1 million Euro (Bundesanstalt für Arbeit, 2001).
} 
enacted in 1998 as the legal basis for active labour market policy in Germany. ${ }^{4}$ Whereas the earlier studies are based on survey data sets like the German Socio-Economic Panel or the Labour Market Monitor for East Germany, there are three more recent studies based on administrative data from the FEA. The results of the effectiveness of vocational training programmes are mixed in the earlier studies. On the one hand, the studies of Pannenberg (1995), Hübler (1998), and Hujer and Wellner (2000) for example find negative or insignificant short- to medium-term employment effects. ${ }^{5}$ On the other hand, the studies of Pannenberg and Helberger (1997), Fitzenberger and Prey (1997), and Prey (1999) establish positive effects. This ambivalence in the results may be due to the limited information of the panel data sets (small sample sizes) as well as to a sensitivity of the results to the different parametric assumptions. More recently, Speckesser (2004), Fitzenberger and Speckesser (2005), and Lechner, Miquel, and Wunsch (2005) have analysed the effects of vocational training programmes based on informative administrative data from the FEA similar to the data used in this study. Whereas Speckesser (2004) and Fitzenberger and Speckesser (2005) restrict their analyses to one specific type of vocational training programmes (provision of specific professional skills and techniques), the study of Lechner, Miquel, and Wunsch (2005) is more comprehensive. Speckesser (2004) analyses the effects of programmes that have started during the years 1993 and 1994 for persons who have become unemployed between 1992 and 1994. He estimates the effects for up to 36 months after programmes have started and finds negative effects shortly after programmes have started and insignificant treatment effects later on. In constrast, Fitzenberger and Speckesser (2005) analyse the employment effects of the programmes for participants whose spell of receiving unemployment benefits starts in 1993 and who were employed shortly before. They establish positive employment effects about 20 months after programmes have started. In addition, Lechner, Miquel, and Wunsch (2005) find positive treatment effects of vocational training programmes accomplished during 1993 and 1994 in the long-run (eight years after programme start). However, the estimated effects refer to programmes in a period before the important reform of the legal basis was enacted in 1998. Therefore, it may be questionable if those estimates could provide evidence of the efficiency of the contemporary vocational training programmes of Social Code III. Furthermore, the changes of the labour market situation that have taken place during the last years complicate the comparison of the results.

In this paper, we analyse the effects of vocational training programmes on the individual transition from unemployment to employment in Eastern Germany. We base our analysis on an inflow sample into unem-

\footnotetext{
${ }^{4}$ In the former legal basis, the Work Support Act (Arbeitsförderungsgesetz), vocational training programmes were called Fortbildung und Umschulung ( FuU).

${ }^{5}$ The studies of Hübler (1997), Staat (1997), Fitzenberger and Prey (1998), Kraus, Puhani, and Steiner (1999), and Lechner (1999; 2000) are in line with these findings.
} 
ployment in the last quarter of 1999 and the observations are followed until December 2002. For that reason, we are able to analyse vocational training programmes according to Social Code III and our estimates should provide evidence for contemporary programmes. We apply an evaluation approach in the timing of events methodology. As Abbring and van den Berg (2003) have shown, the timing of events conveys useful information for the identification of the treatment effects. The econometric model is based on a bivariate mixed proportional hazard model that accounts for observed and unobserved factors. A further advantage of the model is the ability to examine the way how individual training effects change over time. Recently, similar approaches have been applied in a set of studies for other countries, like Bonnal, Fougere, and Serandon (1997) for France, van Ours (2001) for Slovakia, Lalive, van Ours, and Zweimüller (2002) for Switzerland and Richardson and van den Berg (2001a) for Sweden. A comprehensive survey on the methodology can be found in van den Berg (2001).

We estimate the impacts of vocational training programmes on the individual unemployment duration in two ways. In a first step, for the basic model we assume the treatment effect to be time-invariant, i.e. to be a permanent shift of the individual hazard rate to leave unemployment for employment from the moment the treatment has started. However, this assumption may be too strong if we assume participants to be willing to complete their programmes. Therefore, we have to expect that the participants experience 'locking-in'

effects whilst on the programme. For that reason, we estimate time-varying treatment effects in a second step, the extended model. Our results could not affirm the positive findings of programmes accomplished in the 1990s as stated by Lechner, Miquel, and Wunsch (2005) and Fitzenberger and Speckesser (2005). In contrast, taking account of unobserved heterogeneity provides evidence that programmes prolongate the individual unemployment duration. Furthermore, the results of the extended model tend to approve the expected 'locking-in' effects associated with participation.

The remainder of this paper is organised as follows: Section two gives some stylised facts of vocational training programmes in Eastern Germany. The third section presents the econometric methodology. In section four we describe the available data. The results of our empirical application are given in section five. The final section concludes.

\section{Stylised Facts on Vocational Training Programmes}

The main purpose of ALMP is the permanent integration of unemployed persons into regular employment, i.e. they should improve the matching on the labour market. To achieve this goal, ALMP have three main 
functions (cf. Calmfors (1994)): First, they have to adjust the qualification of the unemployed individuals to the demand of vacant occupations. Second, ALMP are used to maintain or increase the search efforts of the unemployed persons. Third, participation as a substitute for regular employment should be arranged in the awareness of the demand side to signal the willingness to work and the productivity of the participant.

Vocational training programmes are primarily oriented according to the first objective, but might also achieve the others. They aim at adjusting the individual qualification to modified requirements on the labour market in order to improve the employment probabilities. Alternatively, they offer a qualification to individuals without a completed professional training. The legal basis of vocational training programmes in Germany is $\S \S 77-96,153-159$, and 417 Social Code III (Sozialgesetzbuch III, SGB III). Unlike the former regulations in the Work Support Act (replaced by SGB III in 1998), there is no distinction between further training and retraining measures. Financial support is usually provided as a maintenance allowance and for the coverage of the direct costs like course costs, learning material, travel costs, or costs for child care etc. Financial support can be obtained by employed and unemployed individuals, if the programmes are necessary in order to bring the unemployed back to work or to avoid unemployment of someone directly threatened by it. It can also be obtained to offer a qualification to someone without a completed professional training. The eligibility rules for participation contain former episodes of employment, an individual counselling and the approval of the scheme by the local labour office. Vocational training programmes for individuals without completed professional training can also be offered to individuals with completed professional training but with no work experience in their profession for more than six years. The 'former duration of employment' rule is accomplished if the individual has contributed at least twelve months of the last three years to the unemployment insurance and fulfils the eligibility rules for unemployment benefits. Several exceptions reduce the strictness of this rule. Full maintenance allowance is granted for individuals in full-time vocational training programmes. Individuals who participate in part-time programmes can achieve partial maintenance allowance. The duration of vocational training programmes that contain a professional training should be up to two-thirds of the regular duration. Other programmes are in general restricted to twelve months of promotion. Vocational training programmes must conclude with a certification that attests the qualification of the participant. The local labour offices are obligated to do quality checks of the courses.

Theoretically, vocational training programmes should positively affect the individual's qualification, productivity and thus the individuals set of attainable jobs. They should decelerate or even reverse the decay of human capital during times of unemployment. Furthermore, they might improve job search skills through preparation of job applications and interviews. Since long-term unemployment may be regarded as a negative signal towards potential employers, interruption of long-term unemployment episodes might help to 
prevent individuals from permanent 'scars' (Wellner, 2000). On the other hand, participation is joined with individual costs, like hardship of studying, course fees, travel costs, loss of income or leisure. As seen above, the labour office provides financial incentives or compensation for these costs.

Since vocational training programmes transfer qualification, participants normally do not leave the schemes before the regular end. Due to this, we expect the search intensity to be reduced to a minimum during programmes. From their overview on studies evaluating vocational training programmes and the results of an aggregated impact analysis, Hagen and Steiner (2000) conclude that the extensive use of vocational training programmes in Eastern Germany raises the unemployment. The programmes might also suffer from the systematic 'locking-in' effects. Thus, they recommend shorter programme durations. This recommendation agrees with the conclusions from international experiences. From their OECD countries experiences review, Martin and Grubb (2001) note four crucial features for effective training programmes: First, there should be a tight targeting on participants, i.e. only people in need and with an expected gain from participation should be treated. Second, programmes should be executed on a relatively small scale. Third, since programmes include a further training or retraining of educated people, they should result in a qualification that is recognised by the market. Fourth, if the treatment contains a strong on-the-job component, links to local employers could be established. In addition, Calmfors, Forslund, and Hemström (2001) note that a rapid expansion of a programme in the presence of very low labour demand is likely to distort the programme incentives if the infrastructure of the programme is not appropriate. In their study for Sweden Richardson and van den Berg (2001b) suggest that the negative 'locking-in' effect more or less offsets a positive treatment effect once the programme has been completed.

\section{Econometric Methodology}

The evaluation of the impact of vocational training on the inflow into regular employment is done with a bivariate duration model. Normalising the point in time when an individual enters unemployment to zero, we measure the duration until the individual enters a regular employment $T_{e}$ and the duration until the individual enters a vocational training programme $T_{p} . T_{e}$ and $T_{p}$ are assumed to be non-negative and continuous random variables with realisations denoted as $t_{e}$ and $t_{p}$.

The durations $T_{e}$ and $T_{p}$ are assumed to vary with the observable characteristics $x$ and the unobservable characteristics $v_{e}$ and $v_{p}$. Although not necessary, the $x$ are assumed to be the same for both distributions, i.e. no exclusion restrictions on $x$ are imposed. Basic assumption for the empirical analysis is that a voca- 
tional training programme affects the distribution of $T_{e}$ if the treatment occurs before the individual leaves unemployment (Abbring and van den Berg, 2003). This implies that the realisation $t_{p}$ affects the distribution of $T_{e}$ in a deterministic way from $t_{p}$ onwards. Thus, we do not only consider the binary information if an individual participates in a programme, but also the additional information on the timing of the treatment within the unemployment spell. As stated by Abbring and van den Berg (2003) this additional information conveys useful information on the treatment effect.

In order to specify the model for the joint distributions $T_{e}, T_{p} \mid x, v_{e}, v_{p}$ we focus on the conditional hazard rates $\theta_{e}\left(T_{e} \mid t_{p}, x, v_{e}\right)$ and $\theta_{p}\left(T_{p} \mid x, v_{p}\right)$. The hazard rate is defined as the probability of exit from a state in a short interval of length $d t$ after $t$, conditional on the state still being occupied at $t$, i.e. $\theta(t)=$ $\lim _{d t \rightarrow 0} \frac{\operatorname{Pr}(t<T \leq t+d t, T>t)}{d t}$. The hazard rate specifies fully the distribution of the durations, where the survivor function is defined as $1-F(t)=\exp \left(-\int_{0}^{t} \theta(s) d s\right)$ and the probability density function as $f(t)=$ $\theta(t)(1-F(t))$. For the specification of the hazard rates we use a mixed proportional hazard model. Basic feature of this model is that the duration dependence, observable and unobservable covariates enter the hazard rate multiplicatively.

$$
\begin{gathered}
\theta_{e}\left(t \mid t_{p}, x, v_{e}\right)=\lambda_{e}(t) \exp \left[x^{\prime} \beta_{e}+\mu\left(t-t_{p}\right) I\left(t>t_{p}\right)+v_{e}\right] \\
\theta_{p}\left(t \mid x, v_{p}\right)=\lambda_{p}(t) \exp \left[x^{\prime} \beta_{p}+v_{p}\right] .
\end{gathered}
$$

The hazard rate for the transition into regular employment at time $t$ (eq. 1) consists of the baseline hazard $\lambda_{e}(t)$ that determines the duration dependence, the systematic part $\exp \left(x^{\prime} \beta_{e}\right)$ that reflects the individual level of the hazard rate conditional on the observable characteristics and the unobserved heterogeneity term $\exp \left(v_{e}\right)$ that implies the individual level of the hazard conditional on the unobserved characteristics.

The treatment effect $\exp \left[\mu\left(t-t_{p}\right) I\left(t>t_{p}\right)\right]$ is specified as the causal effect of $t_{p}$ on the hazard rate $\theta_{e}\left(t \mid t_{p}, x, v_{e}\right)$, with $I\left(t>t_{p}\right)$ as an indicator function taking the value 1 if $t>t_{p}$ (Abbring and van den Berg, 2003). In this notation the treatment effect is defined as a function of the difference $t-t_{p}$ in order to allow the treatment effect to vary over time after the treatment has started. ${ }^{6}$ The treatment effect can be interpreted as a shift of the hazard rate by $\exp \left(\mu\left(t-t_{p}\right)\right)$, that is directly associated with the expected remaining unemployment duration, i.e. a positive treatment effect will shorten the expected remaining unemployment duration. The transition rate from unemployment into training programmes (eq. 2) is analogously specified as a mixed proportional hazard model with the baseline hazard $\lambda_{p}(t)$, the systematic part $\exp \left(x^{\prime} \beta_{p}\right)$ and the unobserved heterogeneity term $\exp \left(v_{p}\right)$.

\footnotetext{
${ }^{6}$ In the notation of Abbring and van den Berg (2003) the treatment effect is also allowed to vary with the moment of treatment and the individual characteristics $x$.
} 
Identification of the treatment effect requires consideration of selectivity with respect to programme participation. Selectivity is present because the individuals we observe to receive a treatment at date $t_{p}$ are a non-random subset of the population. First, this results from the fact that in order to observe $t_{p}$ the individual must not have left unemployment before. Second, since the timing of treatment is affected by $v_{p}$, individuals who are observed to receive a treatment at $t$ are a non-random subset with respect to $v_{p}$. If $v_{p}$ and $v_{e}$ are dependent, the distribution of $v_{e}$ among the participants differs from the corresponding population distribution (Abbring and van den Berg, 2003). If, for example individuals with a relatively high transition rate into employment also have a relatively high transition rate into programmes this may result from two sources. First, a positive treatment effect rises the transition rate into regular employment in the group of participants. Second, individuals with treatment have a relatively high $v_{e}$ and therefore a higher transition into employment rate anyway. In the second case we obviously would observe a positive correlation between $v_{e}$ and $v_{p}$ and therefore a dependence between the indicator function $I\left(t>t_{p}\right)$ and the unobserved heterogeneity term $v_{e}$. Hence, if the possible dependence between $v_{e}$ and $v_{p}$ is ignored the estimate of the treatment effect may be inconsistent (Abbring and van den Berg, 2003). In order to account for the possible dependence in the unobserved heterogeneity terms, we allow $v_{e}$ and $v_{p}$ to follow an arbitrary joint distribution function $G\left(v_{e}, v_{p}\right)$. Abbring and van den Berg (2003) show that with assumptions similar to those made in standard univariate mixed proportional hazard models, the bivariate model in (eq. 1) and (eq. 2) and especially the treatment effect is identified. The identification is nonparametric, since it does not require any parametric assumptions with respect to the baseline hazard and the unobserved heterogeneity distribution (Abbring, van den Berg, and van Ours, 2000). Furthermore the identification does not require exclusion restrictions on $x$ which are often hardly to justify from a theoretical point of view.

The specified model for the transition rates $\theta_{e}$ and $\theta_{p}$ rules out any anticipatory effects of vocational training programmes. An anticipatory effect is given if the realisation $t_{p}$ has an effect on $\theta_{e}$ before $t_{p}$. This may be the case if the individual anticipates a future training and may want to wait for the treatment by reducing his/her search activity (Richardson and van den Berg, 2001a). If anticipatory effects of training programmes exist, our analysis would lead to inconsistent results. However, the main eligibility criteria for vocational training in Germany require that potential participants have small employment chances before treatment. The caseworkers have to place unemployed workers as early as possible into programmes and are obliged to check potential alternative regular employment offers. Moreover, the duration between informing the participant about participation and the actual starting date of the programme is short. Therefore, it is unlikely that individuals voluntarily reduce their employment opportunities for a long period only to obtain a treatment. A second type of ruled out anticipatory effects result, if the individuals anticipate future realisations of $T_{e}$ 
and use this information to modify their optimal strategy, which in turn affects the current transition rate into programmes $\theta_{p}$ (Richardson and van den Berg, 2001a). This is the case if an individual has private information about a future job opportunity and therefore wants to avoid a training. Besides the ruled out anticipatory effects, Abbring and van den Berg (2003) note that there may be ex-ante effects that are not ruled out by the model specification. If the individuals know the determinants of the distribution of $T_{p}$, they may adjust their optimal behaviour in order to become more eligible for a treatment. Although such effects are not estimated by the model they does not lead to inconsistent estimates for the treatment effect. Individuals are allowed to know the determinants of $T_{p}$, but not the realisations of $T_{p}$.

The duration dependence is specified as a piecewise constant for both hazard rates:

$$
\lambda_{j}=\exp \left[\sum_{k=1}^{4} \lambda_{j, k} \cdot I_{k}(t)\right],
$$

where $k$ is a subscript for the time interval and $I_{k}(t)$ is an indicator function that takes the value 1 if $t$ lies in the interval $k$. The intervals used for the analysis are 0-3 months, 3-9 months, 9-18 months and more than 18 months. As we include a constant term in the systematic parts of both hazard rates we normalise $\lambda_{e, 1}$ and $\lambda_{p, 1}$ to zero.

The probability density functions for $T_{e}$ and $T_{p}$ are given by:

$$
\begin{array}{r}
f_{e}\left(t \mid t_{p}, x, v_{e}\right)=\theta_{e}\left(t \mid t_{p}, x, v_{e}\right) \cdot \exp \left[-\int_{0}^{t_{e}} \theta_{e}\left(s \mid t_{p}, x, v_{e}\right) d s\right], \\
f_{p}\left(t \mid x, v_{p}\right)=\theta_{p}\left(t \mid x, v_{p}\right) \cdot \exp \left[-\int_{0}^{t_{p}} \theta_{p}\left(s \mid x, v_{p}\right) d s\right] .
\end{array}
$$

In order to build the likelihood function for the estimation of the model we have to account for censored observations. Thereby we allow only for right censoring, i.e. we only observe that the spell has not been finished until $t$. We define the censoring indicators $\delta_{e}$ and $\delta_{p}$, with $\delta_{e}=1\left(\delta_{p}=1\right)$ if $t_{e}\left(t_{p}\right)$ is right censored. With the parameters $\left(\psi_{e}, \psi_{p}\right) \in \Psi$ the individual likelihood contributions are given by:

$$
\begin{array}{r}
\ell_{e}\left(\psi_{e} ; t, t_{p}, x, v_{e}\right)=f_{e}\left(t \mid t_{p}, x, v_{e}\right)^{\delta_{e}} \exp \left[-\int_{0}^{t_{e}} \theta_{e}\left(s \mid t_{p}, x, v_{e}\right) d s\right]^{1-\delta_{e}}, \\
\ell_{p}\left(\psi_{p} ; t, x, v_{p}\right)=f_{p}\left(t \mid x, v_{p}\right)^{\delta_{p}} \exp \left[-\int_{0}^{t_{p}} \theta_{p}\left(s \mid x, v_{p}\right) d s\right]^{1-\delta_{p}} .
\end{array}
$$

As we assume that $T_{e} \mid x, t_{p}, v_{e}$ is independent from $T_{p} \mid x, v_{p}$ we can write (see van den Berg (2001)): ${ }^{7}$

$$
\ell_{e, p}\left(\psi_{e}, \psi_{p} ; t, x\right)=\int_{e} \int_{p} \ell_{e}\left(\psi_{e} ; t, t_{p}, x, e\right) \cdot \ell_{p}\left(\psi_{p} ; t, x, p\right) d G(e, p) .
$$

\footnotetext{
${ }^{7}$ Since if $f_{e, p}(t \mid x)=\int_{e} \int_{p} f_{e}\left(t \mid t_{p}, x, e\right) f_{p}(t \mid x, p) d G(e, v)$ then $F_{e, p}(t \mid x)=\int_{e} \int_{p} F_{e}\left(t \mid t_{p}, x, e\right) F_{p}(t \mid x, p) d G(e, v)$ and the censoring indicator takes either unity or zero.
} 
Following Heckman and Singer (1984), the arbitrary distribution function $G\left(v_{e}, v_{p}\right)$ can be approximated by a discrete distribution with a finite number of support points. For the empirical analysis we assume that $G\left(v_{e}, v_{p}\right)$ has two points of support for each argument $v_{e}$ and $v_{p}$ with the associated probabilities $\pi_{1}=$ $P\left(v_{e, 1}, v_{p, 1}\right), \pi_{2}=P\left(v_{e, 1}, v_{p, 2}\right), \pi_{3}=P\left(v_{e, 2}, v_{p, 1}\right)$ and $\pi_{4}=P\left(v_{e, 2}, v_{p, 2}\right)$.

The individual likelihood contribution can then be written as:

$$
\begin{aligned}
l_{e, p}\left(\psi_{e}, \psi_{p} ; t, x\right) & =\pi_{1} \cdot \ell_{e}\left(\psi_{e} ; t, t_{p}, x, v_{e, 1}\right) \cdot \ell_{p}\left(\psi_{p} ; t, x, v_{p, 1}\right)+\pi_{2} \cdot \ell_{e}\left(\psi_{e} ; t, t_{p}, x, v_{e, 1}\right) \cdot \ell_{p}\left(\psi_{p} ; t, x, v_{p, 2}\right) \\
& +\pi_{3} \cdot \ell_{e}\left(\psi_{e} ; t, t_{p}, x, v_{e, 2}\right) \cdot \ell_{p}\left(\psi_{p} ; t, x, v_{p, 1}\right)+\pi_{4} \cdot \ell_{e}\left(\psi_{e} ; t, t_{p}, x, v_{e, 2}\right) \cdot \ell_{p}\left(\psi_{p} ; t, x, v_{p, 2}\right) .
\end{aligned}
$$

Estimation is accomplished with the method of maximum likelihood, where the probabilities of the mixing distribution are specified as logistic probabilities: ${ }^{8}$

$$
\begin{aligned}
& \pi_{1}=\frac{1}{1+\exp \left(q_{1}\right)+\exp \left(q_{2}\right)+\exp \left(q_{3}\right)}, \pi_{2}=\frac{\exp \left(q_{1}\right)}{1+\exp \left(q_{1}\right)+\exp \left(q_{2}\right)+\exp \left(q_{3}\right)}, \\
& \pi_{3}=\frac{\exp \left(q_{2}\right)}{1+\exp \left(q_{1}\right)+\exp \left(q_{2}\right)+\exp \left(q_{3}\right)}, \pi_{4}=\frac{\exp \left(q_{3}\right)}{1+\exp \left(q_{1}\right)+\exp \left(q_{2}\right)+\exp \left(q_{3}\right)},
\end{aligned}
$$

where $q_{1}, q_{2}$ and $q_{3}$ are free parameters to be estimated. ${ }^{9}$ The mass points for $v_{e, 1}$ and $v_{p, 1}$ are normalised to zero since a constant term is included in both hazard rates.

\section{Data and Descriptive Results}

\subsection{Data}

Our empirical analysis is based on an inflow-sample of unemployment entrants in the last quarter of 1999 from Eastern Germany. The information is merged from several administrative sources of the Federal Employment Administration (FEA). These sources are the job seekers' data base and an adjusted version for statistical purposes that record the characteristics of all registered job seekers in Germany and are updated monthly with information from the labour offices. The data contains information on socio-demographic characteristics, qualification and placement restraints as well as a short labour market history. In addition to that, we use data from the programme participants' master data set (MTG) to identify episodes of vocational training programmes. Our outcome of interest, the transition to regular employment, is derived from the Employment Statistics Register (Beschäftigtenstatistik, BSt), which includes information on all persons who are

\footnotetext{
${ }^{8}$ We have repeated all estimations from different starting values in order to find the global maximum.

${ }^{9}$ Alternatively, the model could be estimated by a EM-Algorithm as suggested by Heckman and Singer (1984) although the convergence speed is extremely slow.
} 
registered in the social security system. These are all regular employed persons and participants of several ALMP programmes, but no self-employed or pensioners. It is the base for the individual pension claims and contains information on all episodes of dependent employment.

The initial sample contains 30,539 individuals. These individuals are followed until December 2002. To avoid possible influences from former ALMP programmes, we excluded 3,597 individuals who were participating in ALMP before their current unemployment spell. Furthermore, 4,928 individuals participating in other ALMP programmes during the observation period are excluded, since the number of individuals in these programmes is too small for reliable analysis. For homogeneity reasons we restrict the sample to native Germans (352 dropped), without any health restrictions (3,013), and aged between 20 to $50(5,005)$. The remaining dataset contains 13,644 observations.

For these individuals the labour market history in the observation period consists of four possible states: (i) unemployment, (ii) employment, (iii) out of labour force and (iv) participation in a vocational training programme. In the empirical analysis, the unemployment spell ends if an individual finds a regular job or leaves the labour force, i.e. for the participants the time of treatment is not excluded from their unemployment spell. Thereby, we consider only those transitions to regular employment as a success, where the following employment spell lasts for at least six months, which is the usual probation period of an occupation in Germany. This is reasonable, because we are interested in the transition rate into a regular and lasting employment. Due to this consideration, we observe uncensored transitions into (lasting) employment only until June 2002.

The transition to programmes is measured in terms of the duration until the first participation independently of the following treatment duration. Therefore, repeated participations (multiple treatments) are not considered. The duration of unemployment $t_{e}$ is right-censored if the individual leaves the labour force within the observation period. If the unemployment spell is continuing at the end of the observation window, the duration of unemployment is also right-censored. Analogously, the unemployment duration until treatment $t_{p}$ is right-censored if there is no transition to a vocational training programme within the observation period, or if the spell of unemployment ends before the programme starts, $t_{e}<t_{p}$. As noted above, for censored observations we can only observe that the spell has not been finished until the censoring point. In our data, slightly more than a quarter of our observations (27.7\%) have censored unemployment spells until employment $\left(t_{e}\right)$. We have $11.04 \%$ (1,506 individuals) with non-censored unemployment spells until treatment, i.e. participants in vocational training programmes. 


\subsection{Descriptive Results}

Non-parametric estimates of the transition rates into regular employment and programme participation are given in figure 1. The transition rate into regular employment increases in the first three months of the unemployment spell up to about $18 \%$ and than decreases to approximately $2 \%$ after one year. Besides a slightly upturn during the second year it remains stable around this scale for the rest of the observation period. The hazard rate for the transition into programmes oscillates relatively constant between zero and 2 percent for the observation period.

Include figure 1 about here.

As noted above, eligibility for participation normally refers to former employment and completed professional training. Due to that, we assume these characteristics to influence the participation probability. Since the duration of unemployment depends on the individual placement restraints, we employ further covariates that describe the individual situation in the labour market. These additional information include dummies for women, the former occupational group, the educational degree, and the present work experience of the individual. Furthermore we account for the number of children, the individual's age in January 2000, the duration of the last employment spell, and the number of (unsuccessful) placement propositions by the local labour office. We distinguish between six occupational groups, namely i) agriculture, plant cultivation and fishery industry, ii) miners and mining industry, iii) manufacturing professions, iv) technical occupations, and v) services, where we use vi) all other professions as the reference category in the estimation. To analyse possible effects of different levels of educational degrees, where a higher educational degree implies a higher value of worker's human capital, we consider six classes of educational groups. The reference category are individuals without any professional training and without a General Certificate of Secondary Education (CSE). The second class are individuals that also miss a completed professional training, but hold a CSE. Individuals with industrial training are in the third class. The fourth class are persons with a full-time vocational school degree. Workers with a polytechnic degree are represented by the fifth class. The highest human capital value conditional on the educational degree is covered by the last category, which contains all individuals with college or university certificates.

Include table 1 about here.

Table 1 presents descriptive results for the selected characteristics for the total sample and the treatment and non-treatment group separately. While the majority of variables denotes no clear differences between 
participants and non-participants, some particularities should be noticed. First, the proportion of women in the participating group is about ten percent higher than in the group of non-participants. This might reflect a possible gender discrimination in the employment probabilities due to lower employment probabilities for women and consequently a higher degree of necessary promotion by vocational training programmes. Second, the duration of the last employment spell before unemployment is much higher for the participating group. A possible reason could be the eligibility criteria for participation that rely on an existent professional degree and contributions to the unemployment insurance. Third, even though the shares of individuals from the mining industry and technical occupations are small in the population, there are two times as many 'miners' and about one and a half times as many individuals from technical occupations in the treatment group. This is not surprising since vocational training programmes should assist the structural reorganisation of the labour market. Unfortunately, despite the mentioned differences in the observable characteristics, there may be further unobservable determinants of the selection process that should be considered in the analysis.

As noted above, courses in general last for twelve months or in cases of programmes with professional training degree up to two thirds of the regular duration. Figure 2 depicts this distribution. Obviously, the majority of courses in the dataset has durations up to twelve months. Furthermore, we can identify three peaks in the period up to this point. A share of $11 \%$ of the programmes lasts no longer than one month, programmes with a duration of six months amount to $13 \%$ of the sample and the modus is at twelve months with a proportion of $15 \%$.

Include figure 2 about here.

\section{Empirical Analysis}

For the empirical analysis of the effects of vocational training programmes we will consider the treatment effects in two different ways. A first reasonable approach common in the empirical literature (see e.g. Richardson and van den Berg (2001a)) is to specify the programme effect on the transition rate into regular employment as a permanent shift of the hazard rate. The analysis of this basic model enables us to investigate the general effect of vocational training as well as the issue of selectivity with respect to programme participation. However, the assumption that treatment affects the transition into regular employment permanently may not hold in reality. Thus, it is reasonable to think of a time-varying treatment effect that differs in magnitude. To check, whether this becomes true, we will extend the basic model in a second step to allow for time-varying treatment effects. 
In the basic model the treatment effect is assumed to be of the form $\exp \left[\mu I\left(t>t_{p}\right)\right]$. Here, the hazard rate shifts permanently by $\exp (\mu)$ if the individual starts treatment. In order to assess the problem of selectivity with respect to programme participation, we compare the estimation results of the model with and without unobserved heterogeneity. For the estimation of the model without unobserved heterogeneity $v_{e}$ and $v_{p}$ are restricted to zero, i.e. only one point of support for the mixing distribution is imposed. Table 2 presents the estimation results for these two models. ${ }^{10}$

Considering the coefficients of the observable characteristics on the transition rate into regular employment we find a significant higher exit rate for married persons and individuals with work experience and a significant lower exit rate for females. The hazard rate declines with age, number of children, the duration of the last employment spell and the number of placement propositions.

Include table 2 about here.

Turning to the coefficients for the occupational groups, we find remarkably larger coefficients for the model accounting for unobserved heterogeneity. In both models the individuals out of the agriculture and fishing industry have the highest exit rate. With respect to the educational degree the largest exit rate results for individuals with a polytechnical degree followed by the college and university graduates. Concerning the transition rate into programmes married persons and individuals with work experience show a higher transition rate. Furthermore the transition rate into programmes declines with age and rises with the number of children, the duration of the last employment spell and the number of placement propositions. Considering the occupational groups we find the largest transition rate for the unemployed from the mining industry. This may primarily result from the fact that vocational training in Eastern Germany is extensively used for structural reorganisation of the labour market. Regarding the coefficients for the educational degree the largest transition rate is given for individuals with a full time vocational degree, followed by individuals with an industrial training. The results show that vocational training is primarily assigned to individuals with a usual vocational degree and not to high or low educated individuals.

The treatment effect estimated from the model without unobserved heterogeneity ( $\mu=-0.93$ ) is negative and significant. Since $\exp (-\mu)=0.3945$, the transition rate is permanently reduced by $60 \%$ at the point in time the individual enters treatment. Allowing for unobserved heterogeneity the negative effect becomes much stronger with $\exp (-\mu)=0.1746$. Hence accounting for unobserved heterogeneity the hazard shifts by more than $80 \%$.

\footnotetext{
${ }^{10}$ In addition, we have also estimated models with more than two points of support for the unobserved heterogeneity. Unfortunately, it was not possible to find a global maximum in these models.
} 
Considering the distribution of the unobserved heterogeneity, we find for $19.3 \%$ percent a positive selection, i.e. people with good labour market opportunities are more often selected to participate in vocational training programmes $\left(v_{e 1}=-5.385, v_{p 1}=-7.291\right)$. 38.5\% have good labour market opportunities, but a low transition rate into programmes $\left(v_{e 1}=-5.385, v_{p 2}=-10.891\right)$. For only $6.1 \%$ of the individuals a low transition rate into employment and a high transition rate into programme participation $\left(v_{e 2}=-8.008, v_{p 1}=\right.$ -7.291 ) can be calculated. Therefore, individuals with low labour market opportunities seem to be less eligible to participate. Finally, $36 \%$ have for both transition rates simultaneously a low heterogeneity term $\left(v_{e 2}=-8.008, v_{p 2}=-10.891\right)$. The positive programme selectivity is stated more explicitly by the fact, that almost $75 \%$ of the individuals with a high transition rate into programme participation have also a high transition rate into regular employment.

As noted above, the estimated treatment effect so far is a constant shift of the hazard rate from the beginning of the training programme. However, defining the treatment effect in this way may be inappropriate for the following reasons. First, during programmes participating individuals must be expected to have a reduced search intensity for regular employment, i.e. one has to expect a 'locking-in' effect of the programme. Second, an effect of a training programme should be expected to vanish as time goes on. In order to allow for a time-varying treatment effect we specify the treatment effect $\exp \left[\mu\left(t-t_{p}\right) I\left(t>t_{p}\right)\right]$ as a piecewise constant with two intervals. In particular we define the treatment effect as $\exp \left[\mu_{1} I\left(t_{p}<t \leq t_{p}+c\right)+\mu_{2} I\left(t>t_{p}+c\right)\right]$ where $c$ is a exogenously given threshold. The hazard is shifted by $\exp \left(\mu_{1}\right)$ in the period $\left[t_{p}, t_{p}+c\right)$ and by $\exp \left(\mu_{2}\right)$ in the period $\left[t_{p}+c, \infty\right)$. The extended model is estimated using the same specification for the baseline hazard, the systematic part and the unobserved heterogeneity. We estimated three models where the exogenous given threshold $c$ was set to 3, 6, and 12 months respectively. The parameters are presented in table 3 .

Regarding the estimates for the baseline hazard, the observable characteristics and the unobserved heterogeneity the results are similar to the basic model with unobserved heterogeneity. With respect to the treatment effects we find some differences of the extended models in comparison to the basic model. First, for the model where $c$ is set to 3 the negative treatment effect for $\mu_{1}$ is larger than in the basic model that shifts the hazard rate to about 11 percent of the reference level. In addition, the effect for $\mu_{2}$ is still negative, but not as much as for $\mu_{1}$ (with about 25 percent of the reference level). The same result can be established for the model where $c$ is set to 12 . We find a stronger negative effect for the first twelve months and a weaker effect in the remaining period compared to the basic model $\left(\exp \left(-\mu_{1}\right)=0.1405 / \exp \left(-\mu_{2}\right)=0.3399\right)$. However, for the model where $c$ is set to 6 both treatment effects are not as negative as in the basic model, and the transition rate to employment is reduced within the first six months to about 18.6 percent and to 
about 24.76 percent afterwards.

The results based on the extended model show a stronger reduction of the hazard for the period directly after the programme has started. This suggests that a participation in a vocational training programme is associated with a 'locking-in' effect. As vocational training programmes aim at the qualification and requalification of unemployed persons a completion of the programmes is more probable than for other ALMP measures. Thus, it is reasonable that the transition rate into employment is lowered during the programme period. A further result from the extended model is that apart from a 'locking-in' effect a participation in a vocational training programme lowers the transition rate into employment as the negative $\mu_{2}$ parameter from the extended model with $c=12$ suggests. This effect should be unaffected by a 'locking-in' effect for most of the participants, because the majority of programmes lasts no longer then 12 months.

Summarising the results, vocational training programmes generally increase the unemployment duration of the participants, which becomes obvious from the results of the basic model. The further analysis of the extended model shows that 'locking-in' effects are a serious problem of vocational training programmes. But, even for the period where almost all programmes are finished the results suggest a negative effect of vocational training on the transition rate into employment.

Include table 3 about here.

\section{Conclusion}

Vocational training programmes have been one of the most important measures of ALMP in Eastern Germany. Considering the tense labour market situation and the large scale of vocational training programmes, their effectiveness has to be evaluated. We have analysed the effects of vocational training programmes on the unemployment duration of the participating individuals. Based on an inflow sample into unemployment from the last quarter of 1999 that was followed until December 2002, we applied a timing of events approach. By doing so, we could take account for the timing of treatment within the unemployment spell that affects the distribution of the unemployment duration. The econometric analysis is based on a bivariate mixed proportional hazard model, where the transition rates into employment and into programmes are simultaneously modelled. Selectivity problems with respect to programme participation are solved by allowing the transition rates to depend on observable and unobservable characteristics.

The empirical analysis is conducted in two steps. In the first step, we have chosen the basic model, where the treatment effect is specified as a time invariant shift of the transition rate. The results show a significant 
negative effect of vocational training programmes on the transition rate into employment. In the second step, we have extended the model to allow for a time-varying treatment effect. Although the results imply negative effects of vocational training programmes on the transition rate into employment, too, in particular for the period shortly after the programmes have started the strongest negative impacts can be established. This suggests that 'locking-in' effects are a serious problem of vocational training programmes. Afterwards, the effects are still negative, but less strong.

Several reasons may be responsible for this unsatisfying picture of the efficiency of vocational training programmes in Eastern Germany. There may be a possible stigmatisation of the participants that harms their re-employment probability. Furthermore, if individuals participate who would have found an occupation anyway, the involvement into the programmes may prolongate their unemployment duration artificially. Moreover, one can think of an inchoate design of the programmes for the intended purpose, i.e. the contents taught to the participants are not in line with the demand of the market. All these arguments may be to some extent responsible for the obtained failure of the programmes. However, an important reason must be seen in the actual labour market situation in Eastern Germany, where unemployment originates from a shortage of labour demand. Therefore, vocational training programmes that aim at adjusting the structure of labour supply to the requirements of labour demand seem not to be effective.

\section{References}

Abbring, J. H., ANd G. J. VAn DEN Berg (2003): “The Nonparametric Identification of Treatment Effects in Duration Models," Econometrica, 71(5), 1491-1517.

Abbring, J. H., G. J. van Den BerG, And J. C. van Ours (2000): “The Effect of Unemployment Insurance Sanctions on the Transition Rate from Unemployment to Employment," Working Paper, Department of Economics, Vrije Universiteit Amsterdam.

BENDER, S. (2002): “Die IAB-Beschäftigtenstichprobe," in IAB-Kompendium Arbeitsmarkt- und Berufsforschung, ed. by G. Kleinhenz, pp. 3-12. IAB - Beiträge zur Arbeitsmarkt- und Berufsforschung 250, Nuremberg.

Bonnal, L., D. Fougere, And A. Serandon (1997): "Evaluating the Impact of French Policies on Individual Labor Market Histories," Review of Economic Studies, 64, 683-713. 
Bundesanstalt für Arbeit (2001): Arbeitsmarkt 2000 - Amtliche Nachrichten der Bundesanstalt für Arbeit 49. Jahrgang, Nürnberg.

CAlmfors, L. (1994): “Active Labour Market Policy and Unemployment - A Framework for the Analysis of Crucial Design Features," OECD Economic Studies, 22, 7-47.

Calmfors, L., A. Forslund, And M. Hemström (2001): "Does Active Labour Market Policy Work? Lessons from the Swedish Experiences," Swedish Economic Policy Review, 85, 61-124.

Fitzenberger, B., And H. Prey (1997): “Assessing the Impact of Training on Employment,” ifo-Studien, $43,71-116$.

(1998): "Beschäftigungs- und Verdienstwirkungen von Weiterbildungsmaßnahmen im ostdeutschen Transformationsprozeß: Eine Methodenkritik.," in Qualifikation, Weiterbildung und Arbeitsmarkterfolg. ZEW-Wirtschaftsanalysen Band 31, ed. by F. Pfeiffer, and W. Pohlmeier, pp. 39-95. Nomos-Verlag.

Fitzenberger, B., And S. SPeckesser (2005): "Employment Effects of the Provision of Specific Professional Skills and Techniques in Germany,” Working Paper, Goethe University Frankurt.

GRITZ, M. (1993): “The Impact of Training on the Frequency and Duration of Employment," Journal of Econometrics, 57, 21-51.

Hagen, T., And V. Steiner (2000): Von der Finanzierung der Arbeitslosigkeit zur Förderung von Arbeit Analysen und Empfehlungen zur Arbeitsmarktpolitik in Deutschland. Nomos Verlagsgesellschaft, BadenBaden.

Heckman, J. J., And B. Singer (1984): “A Method for Minimizing the Impact of Distributional Assumptions in Econometric Models for Duration Data," Econometrica, 52(2), 271-320.

HÜBLER, O. (1997): “Evaluation beschäftigungspolitischer Maßnahmen in Ostdeutschland," Jahrbücher für Nationalökonomie und Statistik, 216, 21-44.

(1998): "Berufliche Weiterbildung und Umschulung in Ostdeutschland - Erfahrungen und Perspektiven," in Qualifikation, Weiterbildung und Arbeitsmarkterfolg. ZEW-Wirtschaftsanalysen Band 31, ed. by F. Pfeiffer, and W. Pohlmeier, pp. 97-131. Nomos-Verlag.

Hujer, R., And M. Wellner (2000): "Berufliche Weiterbildung und individuelle Arbeitslosigkeitsdauer in West- und Ostdeutschland: Eine mikroökonometrische Analyse," Mitteilungen aus der Arbeitsmarktund Berufsforschung, 33(3), 405-420. 
Kalbfleisch, J. D., And R. L. Prentice (2000): The Statistical Analysis of Failure Time Data. John Wiley and Sons, New York. Chichester. Brisbane. Toronto. Singapore, 2 edn.

Kraus, F., P. Puhani, and V. Steiner (1999): "Employment Effects of Publicly Financed Training Programs - The East German Experience," Jahrbücher für Nationalökonomie und Statistik, 219, 216248.

LAlive, R., J. C. VAN OURS, AND J. ZWeimÜLler (2002): “The Impact of Active Labor Market Programs and Benefit Entitlement Rules on the Duration of Unemployment,” Working Paper, Institute for Empirical Research in Economics, University Zurich.

Lancaster, T. (1990): The Econometric Analysis of Transition Data. Cambridge University Press, Cambridge, New York, Oakleigh.

LECHNER, M. (1999): "Earnings and Employment Effects of Continuous Off-the-Job Training in East Germany After Unification,” Journal of Business Economic Statistics, 17, 74-90.

(2000): “An Evaluation of Public Sector Sponsored Continuous Vocational Training Programs in East Germany," Journal of Human Resources, Spring, 347-375.

Lechner, M., R. Miquel, And C. Wunsch (2005): “The Curse and Blessing of Training the Unemployed in a Changing Economy - the Case of East Germany After Unification," Discussion Paper No. $14 / 2005$, IAB.

Lechner, M., AND J. A. SMith (2005): "What is the Value Added by Caseworkers," Labour Economics, forthcoming.

Martin, J. P., And D. Grubb (2001): “What Works and For Whom: A Review of OECD Countries' Experiences with Active Labour Market Policies,” Working Paper 2001:14, IFAU.

PAnnenberg, M. (1995): Weiterbildungsaktivitäten und Erwerbsbiographie - Eine empirische Analyse für Deutschland. Campus-Verlag, Frankfurt, New York.

Pannenberg, M., and C. Helberger (1997): “Kurzfristige Auswirkungen staatlicher Qualifizierungsmaßnahmen in Ostdeutschland: Das Beispiel Fortbildung und Umschulung," in Bildung und Arbeit in Ostdeutschland, ed. by D. Timmermann, vol. 249 of Schriften des Vereins für Socialpolitik, pp. 77-97.

PREY, H. (1999): Wirkungen staatlicher Qualifizierungsmaßnahmen. Eine empirische Untersuchung für die Bundesrepublik Deutschland. Paul Haupt-Verlag, Bern, Stuttgart, Wien. 
Richardson, K., AND G. J. VAN DEN BERG (2001a): “The Effect of Vocational Employment Training on the Individual Transition Rate from Unemployment To Work," Swedish Economic Policy Review, 8(2), 175-213.

(2001b): "Swedish Labor Market Training and the Duration of Unemployment," Working Paper, IFAU-Uppsala.

SPECKeSSER, S. (2004): "Using Social Insurance Data for the Evaluation of Active Labour Market Policy: Employment Effects of Further Training for the Unemployed in Germany,” Working Paper, University of Mannheim.

STAAT, M. (1997): Empirische Evaluation von Fortbildung und Umschulung - Schriftenreihe des ZEW 21. Nomos Verlagsgesellschaft, Baden-Baden.

VAN DEN BeRG, G. J. (2001): "Duration Models: Specification, Identification, and Multiple Durations," in Handbook of Econometrics, ed. by J. J. Heckman, and E. Leamer, vol. 5, chap. 55, pp. 3381-3462. North-Holland.

VAN Ours, J. C. (2001): "Do Active Labor Market Policies Help Unemployed Workers to Find and Keep Regular Jobs?," in Econometric Evaluation of Labour Market Policies, ed. by M. Lechner, and F. Pfeiffer, pp. 125-152. Physica-Verlag.

Wellner, M. (2000): Evaluating the Employment Effects of Public Sector Sponsored Training in Germany, Wissenschaftliche Schriften. Schulz-Kirchner Verlag, Idstein.

Wunsch, C. (2005): "Labour Market Policy in Germany: Institutions, Instruments and Reforms since Unification,” Working Paper, SIAW. 


\section{Figures and Tables}

Figure 1: Non-PARAmetric Estimates of the Transition Rates to Programme and Employment

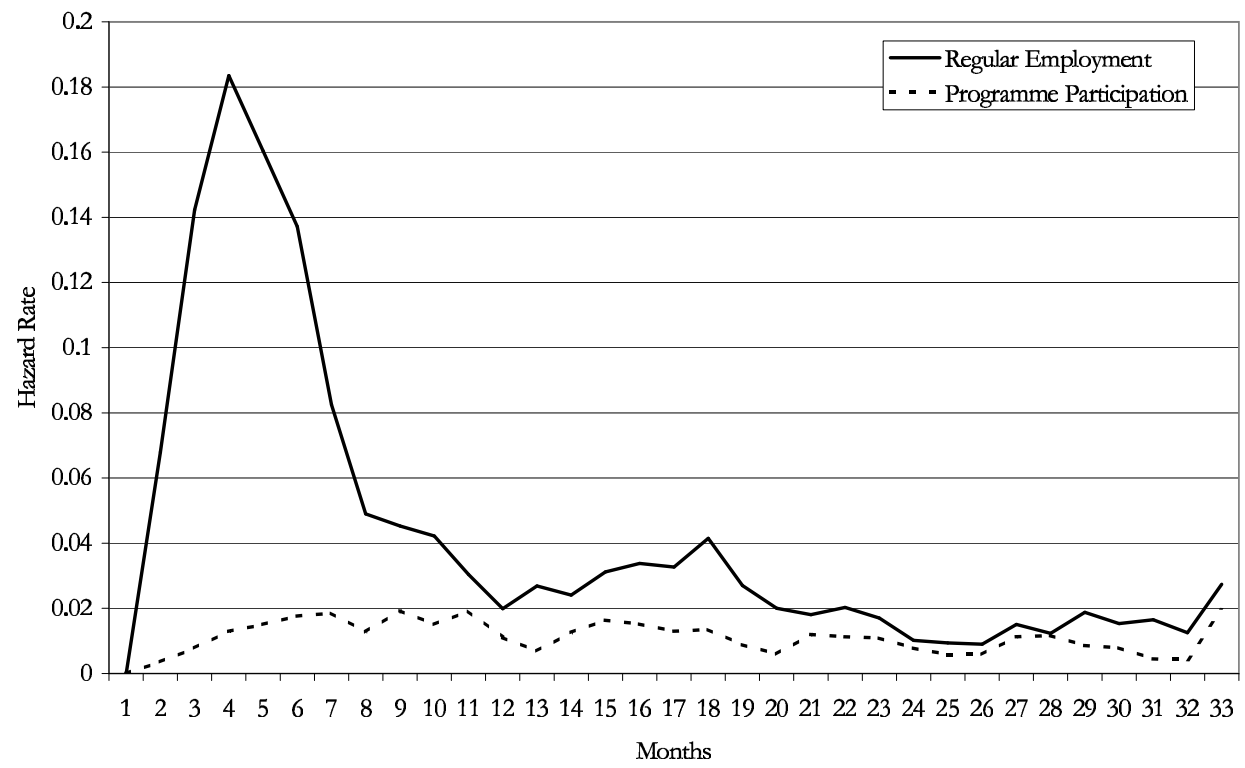

Figure 2: Distribution of Programme Durations

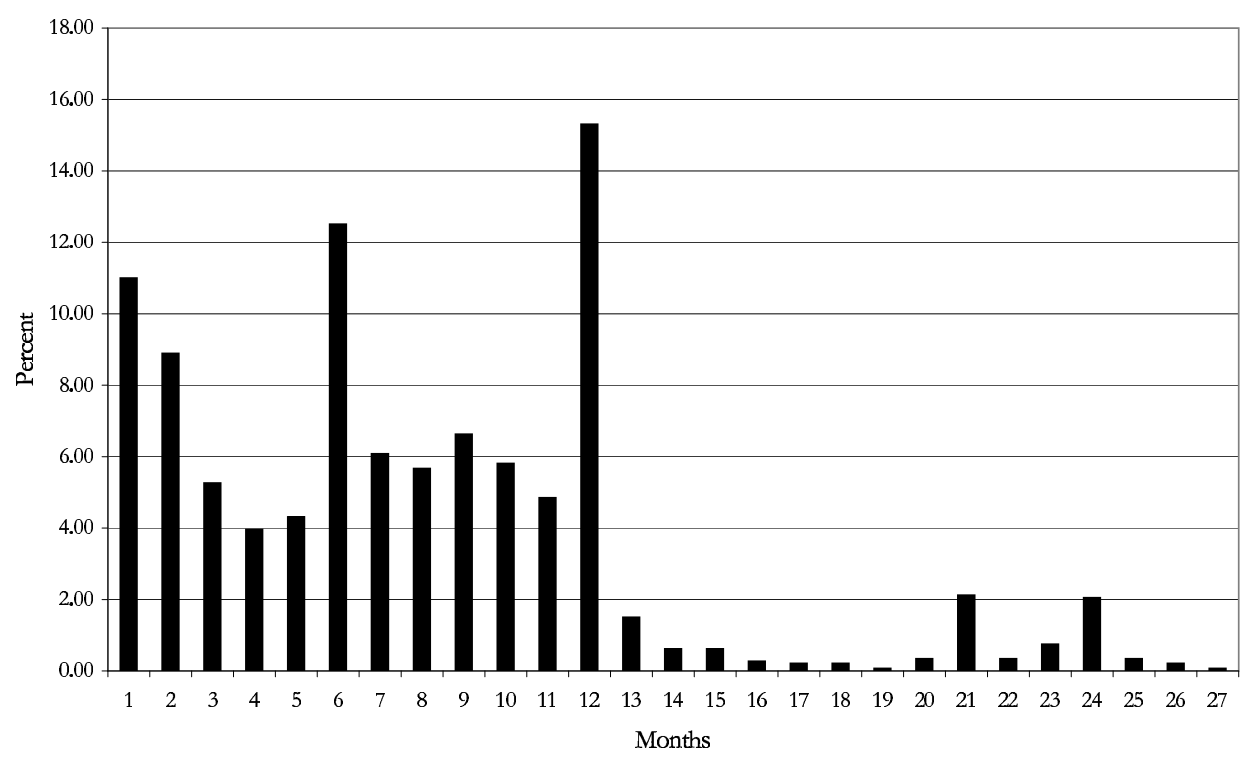


TABle 1: Descriptive Results of Selected CharaCteristics

\begin{tabular}{|c|c|c|c|}
\hline & Total & Participants & $\begin{array}{c}\text { Non- } \\
\text { Participants }\end{array}$ \\
\hline Observations & 13,644 & 1,506 & 12,138 \\
\hline \multicolumn{4}{|l|}{ Share(in \%) } \\
\hline Women & 30.94 & 40.24 & 29.79 \\
\hline Married & 46.50 & 44.49 & 46.75 \\
\hline With work experience & 91.54 & 89.24 & 91.83 \\
\hline \multicolumn{4}{|l|}{ Occupational Group } \\
\hline Agriculture and fishery industry & 9.18 & 3.98 & 9.82 \\
\hline Mining industry & 0.07 & 0.13 & 0.06 \\
\hline Manufacturing industry & 55.50 & 52.72 & 55.84 \\
\hline Technical occupations & 2.31 & 3.59 & 2.15 \\
\hline Service professions & 32.56 & 39.38 & 31.71 \\
\hline Other professions & 0.40 & 0.20 & 0.42 \\
\hline \multicolumn{4}{|l|}{ Educational Degree } \\
\hline No CSE, no professional training & 14.32 & 17.46 & 13.93 \\
\hline CSE, no professional training & 80.80 & 76.10 & 81.38 \\
\hline Industrial training & 0.59 & 1.13 & 0.53 \\
\hline Full-time vocational school degree & 2.10 & 3.39 & 1.94 \\
\hline Polytechnic degree & 0.34 & 0.46 & 0.33 \\
\hline College and university graduates & 1.84 & 1.46 & 1.89 \\
\hline \multicolumn{4}{|l|}{ Mean } \\
\hline Age (years) & 34.44 & 34.07 & 34.48 \\
\hline No. of children & 0.67 & 0.74 & 0.66 \\
\hline Duration of last employment (months) & 23.22 & 28.62 & 22.55 \\
\hline No. of placement propositions & 2.27 & 2.80 & 2.21 \\
\hline
\end{tabular}


TABle 2: Estimation Results For the BAsic Model

\begin{tabular}{|c|c|c|c|c|}
\hline VARIABLES & COEFF. & $t$-VALUE & COEFF. & $t$-VALUE \\
\hline $\begin{array}{c}\text { Transition rate into regular } \\
\text { employment }\end{array}$ & \multicolumn{2}{|c|}{$\begin{array}{c}\text { Without unobserved } \\
\text { heterogeneity }\end{array}$} & \multicolumn{2}{|c|}{$\begin{array}{l}\text { With unobserved } \\
\text { heterogeneity }^{1}\end{array}$} \\
\hline$\lambda_{e, 2}$ & 1.992 & 55.81 & 2.564 & 66.28 \\
\hline$\lambda_{e, 3}$ & 0.663 & 15.34 & 2.310 & 35.34 \\
\hline$\lambda_{e, 4}$ & 0.239 & 4.95 & 2.277 & 27.48 \\
\hline$\mu$ & -0.935 & -17.64 & -1.745 & -14.59 \\
\hline$v_{e}$ & & & -2.623 & -41.72 \\
\hline Constant & -5.114 & -21.98 & -5.385 & -15.75 \\
\hline Women & -0.586 & -21.11 & -0.757 & -17.59 \\
\hline Married & 0.376 & 14.55 & 0.430 & 10.27 \\
\hline Age & -0.009 & -6.66 & -0.010 & -4.44 \\
\hline No. of children & -0.036 & -3.04 & -0.075 & -3.89 \\
\hline Duration of last employment spell & -0.001 & -4.63 & -0.001 & -3.63 \\
\hline No. of placement propositions & -0.030 & -10.37 & -0.043 & -9.80 \\
\hline \multicolumn{5}{|l|}{ Occupational Group ${ }^{2}$} \\
\hline Agriculture and fishery industry & 1.495 & 6.61 & 2.068 & 6.20 \\
\hline Mining industry & 0.736 & 1.58 & 1.625 & 2.74 \\
\hline Manufacturing industry & 0.887 & 3.95 & 1.301 & 3.92 \\
\hline Technical occupations & 0.788 & 3.33 & 1.442 & 4.05 \\
\hline Service professions & 0.866 & 3.85 & 1.272 & 3.83 \\
\hline \multicolumn{5}{|l|}{ Educational Degree ${ }^{3}$} \\
\hline CSE, no professional training & 0.524 & 16.22 & 0.700 & 13.47 \\
\hline Industrial training & 0.420 & 3.00 & 0.426 & 2.13 \\
\hline Full-time vocational school degree & 0.502 & 6.08 & 0.677 & 4.83 \\
\hline Polytechnic degree & 0.700 & 3.95 & 0.858 & 3.50 \\
\hline College or university graduate & 0.440 & 5.22 & 0.796 & 5.26 \\
\hline Work experience & 0.332 & 8.13 & 0.563 & 8.18 \\
\hline Transition rate into programmes & \multicolumn{2}{|c|}{$\begin{array}{l}\text { Without unobserved } \\
\text { heterogeneity }\end{array}$} & \multicolumn{2}{|c|}{$\begin{array}{l}\text { With unobserved } \\
\text { heterogeneity }^{1}\end{array}$} \\
\hline$\lambda_{p, 2}$ & 2.484 & 16.58 & 2.777 & 18.12 \\
\hline$\lambda_{p, 3}$ & 2.519 & 16.66 & 3.643 & 20.82 \\
\hline$\lambda_{p, 4}$ & 2.085 & 13.40 & 4.120 & 17.29 \\
\hline$v_{p}$ & & & -3.600 & -20.18 \\
\hline Constant & -7.923 & -13.03 & -7.291 & -9.63 \\
\hline Women & -0.006 & -0.09 & -0.093 & -0.93 \\
\hline Married & 0.131 & 2.06 & 0.188 & 2.04 \\
\hline Age & -0.013 & -3.76 & -0.023 & -4.21 \\
\hline No. of children & 0.071 & 2.61 & 0.074 & 1.84 \\
\hline Duration of last employment spell & 0.002 & 4.78 & 0.003 & 4.91 \\
\hline No. of placement propositions & 0.013 & 2.47 & 0.015 & 1.69 \\
\hline \multicolumn{5}{|l|}{ Occupational Group ${ }^{2}$} \\
\hline Agriculture and fishery industry & 0.902 & 1.52 & 1.596 & 2.20 \\
\hline Mining industry & 2.177 & 2.38 & 3.995 & 3.88 \\
\hline Manufacturing industry & 1.371 & 2.36 & 2.225 & 3.14 \\
\hline Technical occupations & 1.656 & 2.77 & 2.755 & 3.78 \\
\hline
\end{tabular}


TABLE 2: (CONTINUED)

\begin{tabular}{l|rr|rr}
\hline VARIABLES & COEFF. & $t$-VALUE & COEFF. & $t$-VALUE \\
\hline \hline Service professions & 1.376 & 2.37 & 2.298 & 3.24 \\
Educational Degree $^{3}$ & & & & \\
CSE, no professional training & 0.117 & 1.68 & 0.101 & 0.87 \\
Industrial training & 0.541 & 2.14 & 0.682 & 2.04 \\
Full-time vocational school degree & 0.531 & 3.29 & 0.757 & 3.08 \\
Polytechnic degree & 0.585 & 1.48 & 0.542 & 1.17 \\
College or university graduate & -0.179 & -0.79 & -0.257 & -0.80 \\
Work experience & 0.011 & 0.12 & 0.083 & 0.51 \\
\hline$q_{1}$ & & & 0.690 & 2.41 \\
$q_{2}$ & & & -1.142 & -5.03 \\
$q_{3}$ & & & 0.623 & 2.92 \\
\hline$\pi_{1}$ & & & 0.193 & \\
$\pi_{2}$ & & & 0.385 & \\
$\pi_{3}$ & & $-41,455.476$ & & $-40,628.619$ \\
$\pi_{4}$ & & & \\
\hline Log-Likelihood: & & & \\
\hline \hline
\end{tabular}

${ }^{1}$ Unobserved heterogeneity is specified by using a discrete distribution with two points of support for each argument $v_{e}$ and $v_{p}$.

${ }^{2}$ The reference for the occupational group categories is other professions.

${ }^{3}$ The reference for the educational degree categories is No CSE, no professional training. 
Table 3: Estimation Results for the Extended Model ${ }^{1}$

\begin{tabular}{|c|c|c|c|c|c|c|}
\hline \multirow{2}{*}{$\begin{array}{c}\text { VARIABLES } \\
\begin{array}{c}\text { Transition rate into regular } \\
\text { employment }\end{array}\end{array}$} & \multicolumn{2}{|c|}{ Coeff. $t$-Value } & \multicolumn{2}{|c|}{ CoefF. $t$-VAlue } & \multicolumn{2}{|c|}{ COEFF. $t$-VALUE } \\
\hline & \multicolumn{2}{|c|}{3 Months } & \multicolumn{2}{|c|}{6 Months } & \multicolumn{2}{|c|}{12 Months } \\
\hline$\lambda_{e, 2}$ & 2.579 & 65.71 & 2.593 & 65.42 & 2.577 & 65.40 \\
\hline$\lambda_{e, 3}$ & 2.243 & 34.82 & 2.216 & 34.93 & 2.291 & 35.25 \\
\hline$\lambda_{e, 4}$ & 2.156 & 25.90 & 2.078 & 25.03 & 2.202 & 24.89 \\
\hline$\mu_{1}$ & -2.194 & -13.07 & -1.931 & -14.34 & -1.683 & -13.01 \\
\hline$\mu_{2}$ & -1.397 & -10.08 & -1.079 & -7.38 & -1.396 & -6.59 \\
\hline$v_{e}$ & -2.538 & -41.78 & -2.494 & -42.79 & -2.578 & -40.59 \\
\hline Constant & -5.322 & -15.93 & -5.282 & -16.01 & -5.346 & -15.84 \\
\hline Women & -0.770 & -17.91 & -0.778 & -18.07 & -0.766 & -17.71 \\
\hline Married & 0.447 & 10.65 & 0.457 & 10.85 & 0.441 & 10.44 \\
\hline Age & -0.010 & -4.63 & -0.011 & -4.77 & -0.010 & -4.53 \\
\hline No. of children & -0.076 & -3.92 & -0.076 & -3.91 & -0.076 & -3.91 \\
\hline Duration of last employment spell & -0.001 & -3.63 & -0.001 & -3.57 & -0.001 & -3.62 \\
\hline No. of placement propositions & -0.044 & -10.03 & -0.044 & -10.10 & -0.044 & -9.92 \\
\hline \multicolumn{7}{|l|}{ Occupational Group ${ }^{2}$} \\
\hline Agriculture and fishery industry & 2.037 & 6.27 & 2.020 & 6.31 & 2.048 & 6.23 \\
\hline Mining industry & 1.565 & 2.72 & 1.513 & 2.68 & 1.589 & 2.75 \\
\hline Manufacturing industry & 1.270 & 3.94 & 1.255 & 3.95 & 1.282 & 3.93 \\
\hline Technical occupations & 1.409 & 4.06 & 1.396 & 4.09 & 1.427 & 4.07 \\
\hline Service professions & 1.237 & 3.83 & 1.220 & 3.84 & 1.251 & 3.83 \\
\hline \multicolumn{7}{|l|}{ Educational Degree ${ }^{3}$} \\
\hline CSE, no professional training & 0.711 & 13.70 & 0.718 & 13.80 & 0.710 & 13.56 \\
\hline Industrial training & 0.410 & 2.04 & 0.392 & 1.94 & 0.412 & 2.05 \\
\hline Full-time vocational school degree & 0.679 & 4.85 & 0.688 & 4.87 & 0.681 & 4.85 \\
\hline Polytechnic degree & 0.875 & 3.47 & 0.886 & 3.43 & 0.866 & 3.48 \\
\hline College or university graduate & 0.806 & 5.54 & 0.811 & 5.73 & 0.810 & 5.53 \\
\hline Work experience & 0.563 & 8.22 & 0.565 & 8.23 & 0.563 & 8.16 \\
\hline Transition rate into programmes & \multicolumn{2}{|c|}{3 Months } & \multicolumn{2}{|c|}{6 Months } & \multicolumn{2}{|c|}{12 Months } \\
\hline$\lambda_{p, 2}$ & 2.741 & 17.78 & 2.708 & 17.52 & 2.748 & 17.76 \\
\hline$\lambda_{p, 3}$ & 3.581 & 18.32 & 3.523 & 18.15 & 3.592 & 18.18 \\
\hline$\lambda_{p, 4}$ & 4.073 & 13.72 & 4.017 & 13.65 & 4.085 & 13.62 \\
\hline$v_{p}$ & -3.673 & -15.35 & -3.710 & -16.11 & -3.663 & -14.97 \\
\hline Constant & -7.042 & -9.20 & -6.863 & -8.91 & -7.087 & -9.21 \\
\hline Women & -0.084 & -0.83 & -0.073 & -0.71 & -0.085 & -0.83 \\
\hline Married & 0.188 & 2.00 & 0.186 & 1.94 & 0.187 & 2.00 \\
\hline Age & -0.024 & -4.31 & -0.024 & -4.35 & -0.024 & -4.30 \\
\hline No. of children & 0.071 & 1.72 & 0.069 & 1.63 & 0.072 & 1.74 \\
\hline Duration of last employment spell & 0.003 & 4.85 & 0.003 & 4.80 & 0.003 & 4.86 \\
\hline No. of placement propositions & 0.018 & 2.00 & 0.020 & 2.25 & 0.018 & 1.94 \\
\hline \multicolumn{7}{|l|}{ Occupational Group ${ }^{2}$} \\
\hline Agriculture and fishery industry & 1.558 & 2.11 & 1.517 & 2.03 & 1.564 & 2.13 \\
\hline Mining industry & 4.015 & 3.86 & 4.019 & 3.85 & 4.016 & 3.87 \\
\hline Manufacturing industry & 2.242 & 3.11 & 2.240 & 3.08 & 2.239 & 3.11 \\
\hline
\end{tabular}


TABle 3: (CONTINUEd)

\begin{tabular}{l|rr|rr|rr}
\hline VARIABLES & COEFF. $t$-VAlUE & COEFF. & $t$-VALUE & COEFF. & $t$-VALUE \\
\hline \hline Technical occupations & 2.744 & 3.69 & 2.728 & 3.63 & 2.748 & 3.71 \\
Service professions & 2.316 & 3.21 & 2.317 & 3.18 & 2.314 & 3.22 \\
Educational Degree $^{3}$ & & & & & & \\
CSE, no professional training & 0.064 & 0.55 & 0.037 & 0.32 & 0.0698 & 0.59 \\
Industrial training & 0.610 & 1.83 & 0.563 & 1.69 & 0.6222 & 1.86 \\
Full-time vocational school degree & 0.751 & 3.00 & 0.744 & 2.95 & 0.7520 & 3.01 \\
Polytechnic degree & 0.495 & 1.06 & 0.461 & 0.99 & 0.5032 & 1.08 \\
College or university graduate & -0.303 & -0.92 & -0.335 & -1.01 & -0.2951 & -0.90 \\
Work experience & 0.019 & 0.12 & -0.022 & -0.14 & 0.0303 & 0.18 \\
\hline$q_{1}$ & 1.012 & 3.79 & 1.261 & 4.85 & 0.952 & 3.20 \\
$q_{2}$ & -0.782 & -3.21 & -0.486 & -1.99 & -0.853 & -3.11 \\
$q_{3}$ & 0.914 & 4.15 & 1.157 & 5.09 & 0.851 & 3.48 \\
\hline$\pi_{1}$ & 0.149 & & 0.120 & & 0.157 & \\
$\pi_{2}$ & 0.410 & & 0.424 & & 0.407 & \\
$\pi_{3}$ & 0.068 & & 0.074 & & 0.067 & \\
$\pi_{4}$ & 0.372 & & 0.382 & & 0.368 & \\
\hline Log-Likelihood & $-40,614.90$ & $-40,605.74$ & $-40,626.53$ \\
\hline \hline
\end{tabular}

${ }^{1}$ Unobserved heterogeneity is specified by using a discrete distribution with two points of support for each argument $v_{e}$ and $v_{p}$.

${ }^{2}$ The reference for the occupational group categories is other professions.

${ }^{3}$ The reference for the educational degree categories is No CSE, no professional training. 